\title{
PREPARATION OF SALT-SENSITIVE AND ANTIBACTERIAL HYDROGEL BASED ON QUATERNIZED CELLULOSE
}

\author{
Shaoping Yang, Shiyu Fu, ${ }^{*}$ Xueyun Li, Yiming Zhou, and Huaiyu Zhan \\ Cellulose hydrogels with quaternary ammonium (QA) groups were \\ prepared via the etherification and cross-linking reaction. The structure of \\ the functional hydrogels with QA groups was confirmed with FT-IR. \\ Differential scanning calorimeter (DSC) analysis indicated that there was \\ a large amount of free water in the hydrogels. The hydrogels showed \\ salt-sensitivity behavior, and they also exhibited a strong antibacterial \\ activity toward Escherichia coli.
}

Keywords: Cellulose; Hydrogel; Antibacterial; Salt-sensitive; Quaternary ammonium

Contact information: State Key Laboratory of Pulp and Paper Engineering, South China University of Technology, Guangzhou,510640 China; * Corresponding author. Tel: +86 2087112453

E-mail address: shyfu@scut.edu.cn (S.Fu)

\section{INTRODUCTION}

Hydrogels are three-dimensional cross-linked network polymers that can swell by absorption of many times their weight of water and encompass a wide range of chemical compositions but not dissolve in aqueous solution. They are inherently soft, hydrophilic, and have elastic physical properties similar to those of human tissues, as well as possessing excellent tissue compatibility (Kopeček and Yang 2007), which are prerequisites for many biological applications. Therefore, hydrogels are widely used in wound healing (Obara et al. 2003), tissue engineering (Nuttelman et al. 2008), drug delivery (Hamidi et al. 2008), cellular immobilization (Stabenfeldt et al. 2006), and personal care products (Liu et al. 2008).

These hydrogel materials are suitable for hosting cell function by providing a hydrated environment (Wu et al. 2009). However, the microenvironment of a hydrogel may be ideal for opportunistic bacteria (Salick et al. 2007). Microbes are prevalent in nature, wounds, regenerative tissue, and even in the drugs we take (Roy and Das 2008). Infections caused by these small microbes can range from a mild illness to a fatal one (Potera 1999). Drug delivery or other biomedicine implants are one of the major sources through which the microorganism pathogens invade multicellular organisms (Gristina 1987; Jampala et al. 2008). Therefore, these hydrogel materials for biomedical applications have to be endowed with antibacterial activity towards germs on contact without releasing toxic biocides.

In order to get antibacterial hydrogels, silver nanoparticles (AgNPs) can be applied to the prepared hydrogel. AgNPs are considered to be a non-toxic and environmentally friendly antibacterial material (Mohan et al. 2007). However, those particles have poor binding affinity with surfaces of hydrogels. Some low molecular weight compounds such as quaternary ammonium (QA) salts are commonly employed as antibacterial agents by being absorbed physically in hydrogel (Thorsteinsson et al. 2003), 
but these chemicals can be released easily, thereby causing irritation to skin and residual toxicity, besides being short-term in effectiveness (Dizman et al. 2006).

As compared with these antibacterial agents of low molecular weight, insoluble antibacterial polymers show non-volatile, life-time effectiveness and reduce residual toxicity without leaking any reactive agents (Andresen et al. 2007). Therefore, increasing endeavor has been made during the last decades to synthesize antibacterial polymers through the chemical bonding of low-molecular-weight biocides to polymers. Roy et al. (2008) prepared antibacterial quaternized cellulose (QC) fiber via raft surface graft polymerization. The quaternized cellulose fiber exhibited particularly high antibacterial activity against $E$. coli. It was reported that quaternized celluloses displayed relatively low cytotoxicity and could be considered as promising nonviral gene carriers (Song et al. 2008).

In this paper, we successfully prepared a novel kind of antibacterial and saltsensitive hydrogels based on QC using epichlorohydrin (ECH) as cross-linker. The structure of the hydrogel was analyzed by FT-IR. In addition, the thermal behavior of the hydrogel was characterized by differential scanning calorimetry (DSC). Furthermore, the antibacterial activity, swelling kinetics, and salt-sensitive behaviors of the hydrogels were studied in detail.

\section{EXPERIMENTAL}

\section{Materials and Chemical Analysis}

Cellulose was supplied by Aladdin-Reagent Inc. 3-chloro-2-hydroxypropyltrimethylammonium chloride (CHPTAC) was purchased from Jiaoda Rising Weinan Chemical Industry Co. Ltd., Shanxi, China, and was used as an etherification reagent. All other reagents used in this study were supplied from China Corporation; they were of analytical grade and were used without further purification. Eosin methylene blue agar medium was purchased from Aoboxing Biotech Company Ltd.

\section{Quaternization of Cellulose and QC/ECH Hydrogel Synthesis}

Cellulose solution was prepared according to the literature method (Kuo and Hong 2005). The $10 \mathrm{wt} \% \mathrm{NaOH}$ solutions were prepared by directly mixing solid $\mathrm{NaOH}$ with deionized water and were frozen to $-20^{\circ} \mathrm{C}$. Then $4 \mathrm{~g}$ cellulose was added to $100 \mathrm{~mL}$ the above cooled $\mathrm{NaOH}$ solutions under stirring (2000rpm) for 20min. The cellulose $/ \mathrm{NaOH} / \mathrm{H}_{2} \mathrm{O}$ mixtures were held at $-20^{\circ} \mathrm{C}$ for $5 \mathrm{~h}$. The frozen mixtures were then kept at room temperature until transparent cellulose solutions were obtained. The cellulose solutions were centrifuged at $4000 \mathrm{rpm}$ to exclude the insoluble cellulose.

In the experiment, a certain amount of CHPTAC aqueous solution was added dropwise into the $100 \mathrm{~mL}$ cellulose solution obtained previously. The reaction was held under stirring $(300 \mathrm{rpm})$ at $0^{\circ} \mathrm{C}$. The reaction product was neutralized with aqueous $\mathrm{HCl}$ and dialyzed with dialysis tubes (Mw cutoff 10000) for 7 days. The solution was finally freeze-dried.

The QC/ECH hydrogels were synthesized by the crosslinking reaction with ECH as crosslinker. In the reaction procedure, the $5 \mathrm{wt} \% \mathrm{QC}$ solutions were prepared by 
directly mixing $4 \mathrm{~g}$ solid $\mathrm{NaOH}$ and $10 \mathrm{~g}$ QC with $194 \mathrm{~mL}$ deionized water. Then $10 \mathrm{~mL}$ epichlorohydrin $(\mathrm{ECH})$ was added to $100 \mathrm{~mL}$ QC solutions under stirring (400rpm) for $10 \mathrm{~min}$. The crosslinking reaction was held at $0^{\circ} \mathrm{C}$ for $48 \mathrm{~h}$. The resulting hydrogels (Fig. 1) were washed with deionized water and acetone until the unreacted substances were completely removed.

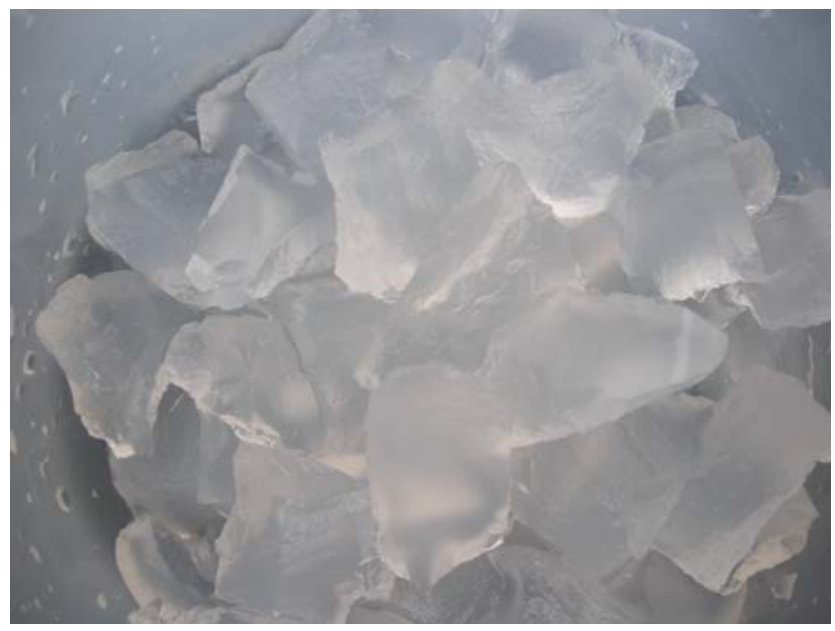

Fig. 1. Micrograph of $\mathrm{QC/ECH}$ hydrogels

\section{Characterization of QCs and QC/ECH Hydrogels}

FT-IR spectroscopy and elemental analysis

The dried samples were compressed into disks with KBr powder. FT-IR spectra of the samples were recorded with an FT-IR spectrometer (Bruker Vector 33, German) from 4000 to $500 \mathrm{~cm}^{-1}$. Nitrogen contents (N\%) of QCs were measured with an elemental analyzer (Vario EL III, Germany). The degree of substitution (DS) value of QC was determined by nitrogen content and calculated according to the literature method (Song et al. 2008).

\section{Thermal analysis of hydrogels}

To reach the swollen equilibrium, hydrogel was immersed in deionized water at room temperature for $24 \mathrm{~h}$. About $8 \mathrm{mg}$ of the swollen equilibrated sample was placed inside a hermetic aluminum pan and sealed tightly by a hermitic aluminum lid after wiping off excess water on the surface with filter paper. The thermal analysis was performed on DSC Q200 (TA Instruments, USA) from $-20^{\circ} \mathrm{C}$ to $120^{\circ} \mathrm{C}$ under a nitrogen flow of $40 \mathrm{ml} \cdot \mathrm{min}^{-1}$ and a heating rate of $2^{\circ} \mathrm{C} \cdot \mathrm{min}^{-1}$.

\section{Morphology observation of hydrogels}

The swollen equilibrium hydrogel samples were freeze-dried under vacuum until all water was sublimed. The freeze-dried samples were fractured carefully in liquid nitrogen, and then fixed on stubs with sputter coated with gold before observation. The morphology of external and fractured surface of samples was observed by scanning electron microscope (Nova NanoSEM 430, Fei Company) with $5 \mathrm{kV}$. 


\section{Swelling Behavior of Hydrogels}

The swelling ratios of the hydrogel samples (diameter: $10 \mathrm{~mm}$ ) were measured at $25^{\circ} \mathrm{C}$ using a gravimetric method. The hydrogel samples were immersed in deionized water or salt solution. Weights of swollen hydrogels at different time were obtained after wiping off the excess water from the surfaces with filter paper. The average value of three measurements from three parallel specimens in the same hydrogel was taken for each sample. The swelling ratio $S W_{t}$ of hydrogels is calculated as follows,

$$
S W_{t}=\left(W_{t}-W_{d}\right) / W_{d}
$$

where $W_{d}$ is the weight of dry hydrogels and $W_{t}$ is the weight of swelling hydrogels at different time.

$S W_{e q}$ of hydrogels was measured by immersing dried hydrogels in deionized water or salt solution. After reaching swollen equilibrium, hydrogels were weighed after removing surface water. $S W_{e q}$ was calculated from the following equation,

$$
S W_{e q}=\left(W_{e q}-W_{d}\right) / W_{d}
$$

where $W_{d}$ is the weight of dry hydrogels and $W_{e q}$ is the weight of the swollen equilibrium hydrogels.

\section{Antibacterial Assessments of QC/ECH Hydrogel}

Preparation of bacterial suspension

The bacterial strain used for the antibacterial activity tests was E. coli, which was kept at $-4^{\circ} \mathrm{C}$ in a freezer. Next the bacteria were cultured $24 \mathrm{~h}$ in $10 \mathrm{~mL}$ of Luria-Bertani liquid medium at $37^{\circ} \mathrm{C}$. The top solution $(5 \mathrm{~mL})$ of the bacterial culture was transferred to a sterile tube and oscillated for $10 \mathrm{~min}$ at $200 \mathrm{r} / \mathrm{min}$ to avoid the bacterial aggregates. Each bacterial suspension was then adjusted in phosphate-buffered saline (PBS, pH 7.0) to an optical density at $625 \mathrm{~nm}\left(10^{9} \mathrm{CFU} / \mathrm{mL}\right)$. The colony-forming units $/ \mathrm{mL}$ were quantified by the measurement of a series of 10 -fold bacterial dilutions plated on Eosin methylene blue agar medium. The bacteria were cultured overnight in a Luria-Bertani liquid medium sterilized by autoclaving at $121^{\circ} \mathrm{C}$ for $15 \mathrm{~min}$. All of the glassware was sterilized in an autoclave at $121^{\circ} \mathrm{C}$ for $20 \mathrm{~min}$.

\section{Antibacterial assessment by direct contact}

A $10 \mu \mathrm{L}$ volume of bacterial suspension $\left(\sim 10^{5} \mathrm{CFU} / \mathrm{mL}\right)$ was placed on the surface of the tested material in a sterilized blank petri dish, as well as the control one, which was made with agar alone. These plates were incubated at $37^{\circ} \mathrm{C}$ for $1 \mathrm{~h}$. During the incubation period, the bacterial suspension was evaporated, and a thin film of bacteria was obtained.

The plates were placed flat, and then $200 \mu \mathrm{L}$ of sterilized Luria-Bertani medium was added to the samples containing the bacteria. Scanning electron microscopy was used for the surface analysis after $24 \mathrm{~h}$ of inoculation at $37^{\circ} \mathrm{C}$. 


\section{RESULTS AND DISCUSSION}

\section{Quaternization of Cellulose and QC/ECH Hydrogel Synthesis}

Quaternized cellulose was prepared by etherifying with CHPTAC in the presence of alkaline catalyst. The reaction process is shown in Scheme 1. The cationization process of cellulose includes two steps (Mohamed. 2006; Song et al. 2008): (a) the chlorohydrin form of the reagent is converted to the epoxy intermediate; and (b) the epoxy reacts with the cellulose to yield the quaternized cellulose, or upon the hydrolysis of the epoxy form, the diol. The reaction conditions play key roles in enhancing the cationization efficiency of cellulose, and the results are given in Table 1.

Table 1. Results of DS of Quaternized Cellulose at $20^{\circ} \mathrm{C}$ in $\mathrm{NaOH}$ Aqueous Solution

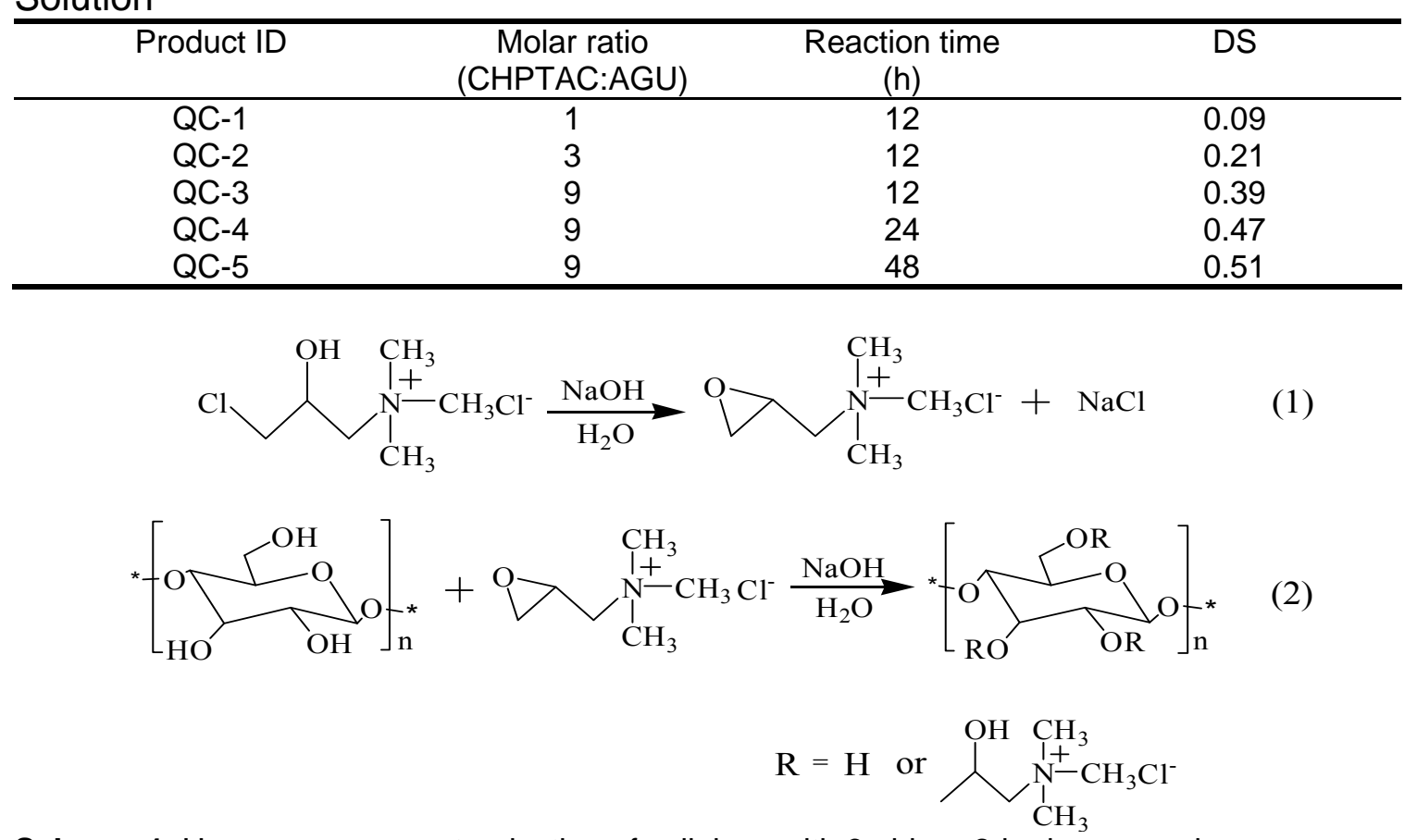

Scheme 1. Homogeneous quaternization of cellulose with 3-chloro-2-hydroxypropyltrimethylammonium chloride (CHPTAC) in $\mathrm{NaOH}$ aqueous solution

QC/ECH hydrogels were synthesized using epichlorohydrin as the cross-linking agent in aqueous alkaline conditions. The proposed reaction mechanism of ECH with QC is shown in Scheme 2. ECH was widely used as a cross-linker to react with the hydroxyl groups of polysaccharides (Bai et al. 2006; Silva et al. 2006; Chang et al. 2008). Under alkaline conditions, the hydroxyl groups of QC become alcoholate anions. The alcoholate anion attacks an epoxy group of $\mathrm{ECH}$ to form a monoether of chloropropanediol. A new epoxy group can form by chloride displacement and rearrangement of the chloropropanediol monoether. When the new epoxy group reacted with the hydroxyl groups of another QC, the cross-linking took place between ECH and QC. In the reaction, there may be some side reactions, for example, some ECH molecules may only react with one hydroxyl group of QC, and some unreacted ECH becomes hydrolyzed to glycerol. 


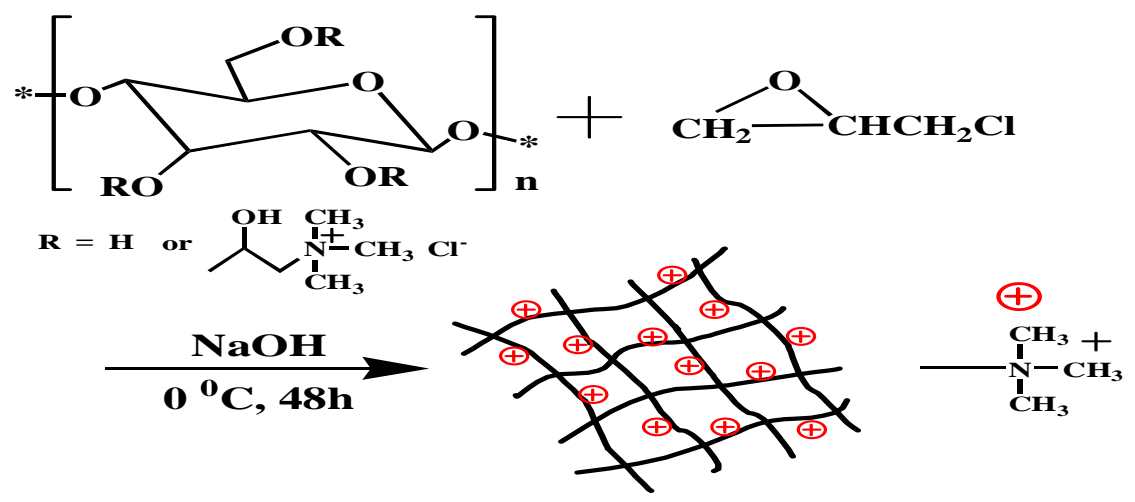

Scheme 2. Preparation of the QC hydrogels with $\mathrm{ECH}$ as crosslinker ( DS of QC used is 0.51 )

\section{Characterization of QCs and QC/ECH hydrogels}

The chemical structures of QCs and QC/ECH hydrogel were characterized by FTIR in the range of 4000 to $400 \mathrm{~cm}^{-1}$. As shown in Fig. 2, the most striking peak of QC was observed at $1479 \mathrm{~cm}^{-1}$, which corresponded to $\mathrm{C}-\mathrm{H}$ symmetric bending of the methyl groups on the quaternary ammonium (Song et al. 2008; Sajomsang et al. 2009). Moreover, the peak of QCs positioned at $1413 \mathrm{~cm}^{-1}$ was referenced as the C-N stretching vibration (Pal et al. 2005; Roy et al. 2008). These results corresponded to the quaternary ammonium salt group grafted on the cellulose backbone. After chemical linkage occurred between ECH and QC, a slight difference was observed between the spectrum of QC and the QC/ECH hydrogel. The peak positions of the methyl groups of ammonium and the C$\mathrm{N}$ stretching vibration shifted from $1479 \mathrm{~cm}^{-1}$ and $1413 \mathrm{~cm}^{-1}$ to $1456 \mathrm{~cm}^{-1}$ and $1378 \mathrm{~cm}^{-1}$ (Pal et al. 2005; Wang et al. 2008; Leelamma and Devaky. 2009). These observations indicate that the crosslinking reaction took place between $\mathrm{ECH}$ and QC.

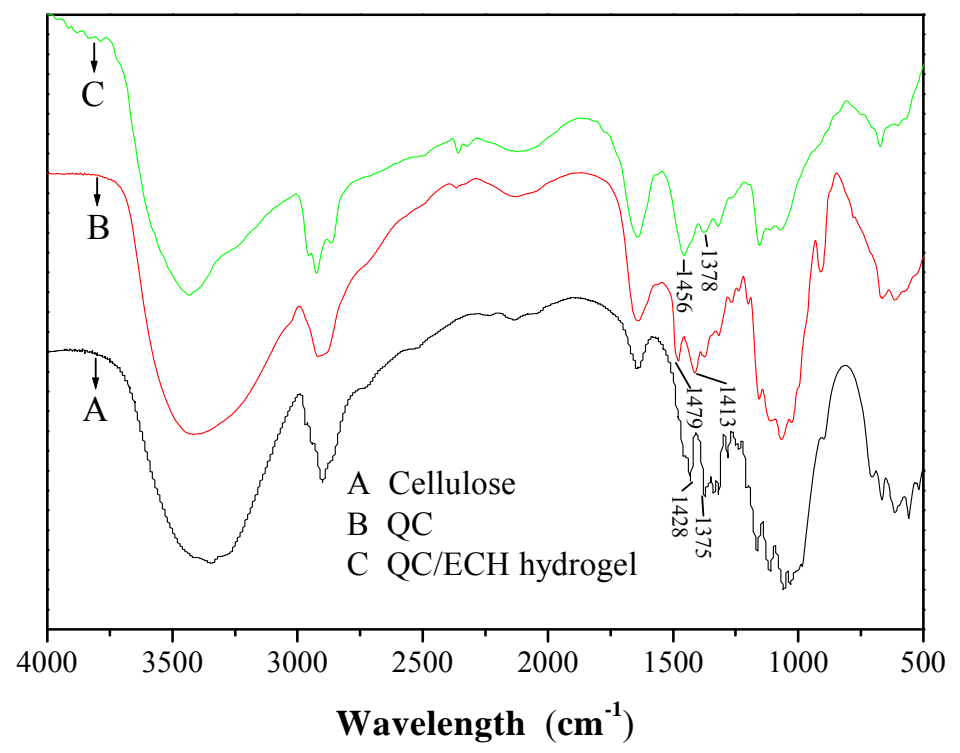

Fig. 2. FT-IR spectra. (A) Cellulose; (B) Quaternized Cellulose; (C) QC/ECH hydrogel 
In general, the state of water in the hydrogel networks can significantly affect the interaction between a hydrogel and other substances, which is critical to their applications in any drug release strategies (Agrawal et al. 2004). The bonding status of water in hydrogels can be analyzed with thermodynamic methods. DSC thermograms of QC gel (5wt \%) and QC/ECH hydrogel are shown in Fig. 3. The DSC curve of QC gel shows a peak at $109.95^{\circ} \mathrm{C}$. After it was crosslinked with $\mathrm{ECH}$, the peak shifted to a lower temperature at $102.13^{\circ} \mathrm{C}$, which can be ascribed to hydrophobic substitution of ECH and a diminution of the number of water binding sites as compared to QC ( $\mathrm{Su}$ et al. 2008). The $\mathrm{QC} / \mathrm{ECH}$ hydrogel shows an endothermic peak between -4 and $4{ }^{\circ} \mathrm{C}$, which is assigned to free water. The fraction of free water to total water is approximated as the ratio of the endothermic peak area between -4 and $4{ }^{\circ} \mathrm{C}$ for the water of the swollen hydrogel to the endothermic melting heat of pure water $(334 \mathrm{~J} / \mathrm{g}$ ) (Sanchez et al. 2004). By consequence, the content of free water and bound water are $78.41 \%$ and $20.48 \%$, respectively, for the crosslinked hydrogel.

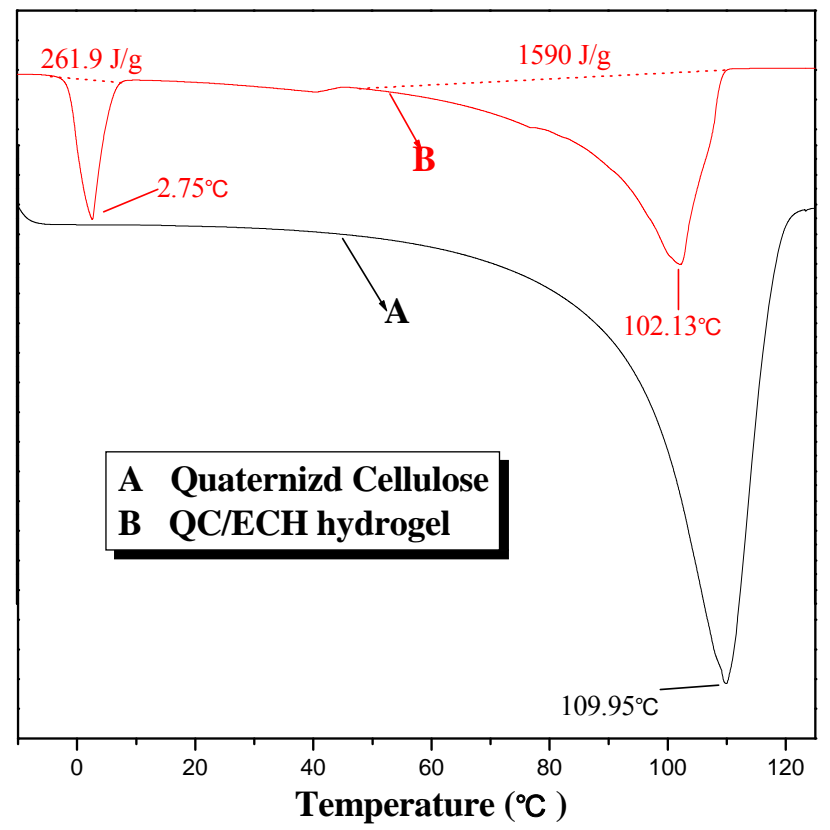

Fig. 3. DSC curves. (A) Quaternized Cellulose; (B) QC/ ECH hydrogel

\section{Effect of Salt Concentrations on Swelling Ratios}

The swelling ratios of QC/ECH hydrogel in different concentrations of salt solutions and deionized water are shown in Fig. 4. As shown, due to their excellent hydrophilicity (Fig. 1) and highly porous network structure (Fig. 5), the QC/ECH hydrogels exhibited a faster swelling rate. Moreover, the QC/ECH hydrogels exhibited good salt sensitivity, because the hydrogels have numerous quaternary ammonium salt groups on their molecular chains. The swelling ratios of hydrogels decreased with the increasing ionic strength of the solutions. It is well documented that the swelling behavior of a hydrogel mainly relates to the characteristics of the external solution, the elasticity of 
the network, and the presence of hydrophilic functional groups (Marandi et al. 2006). A screening effect of the salt solution shielded the cation-cation electrostatic repulsion in the hydrogel network (Zhao et al. 2006). Moreover, increasing salt concentration leads to a decreased osmotic pressure (ionic pressure) difference between the polymer network and the external solution. Therefore, the swelling ratios of hydrogels decreased with the increasing salt concentration.

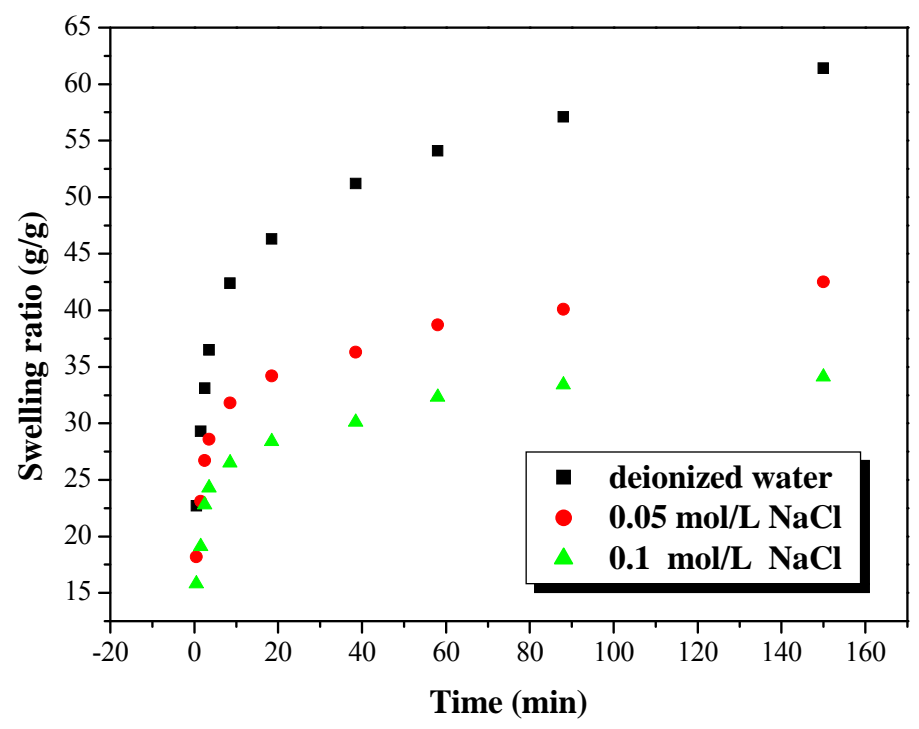

Fig. 4. Effect of concentration of $\mathrm{NaCl}$ solution on swelling ratio of the $\mathrm{QC} / \mathrm{ECH}$ hydrogels

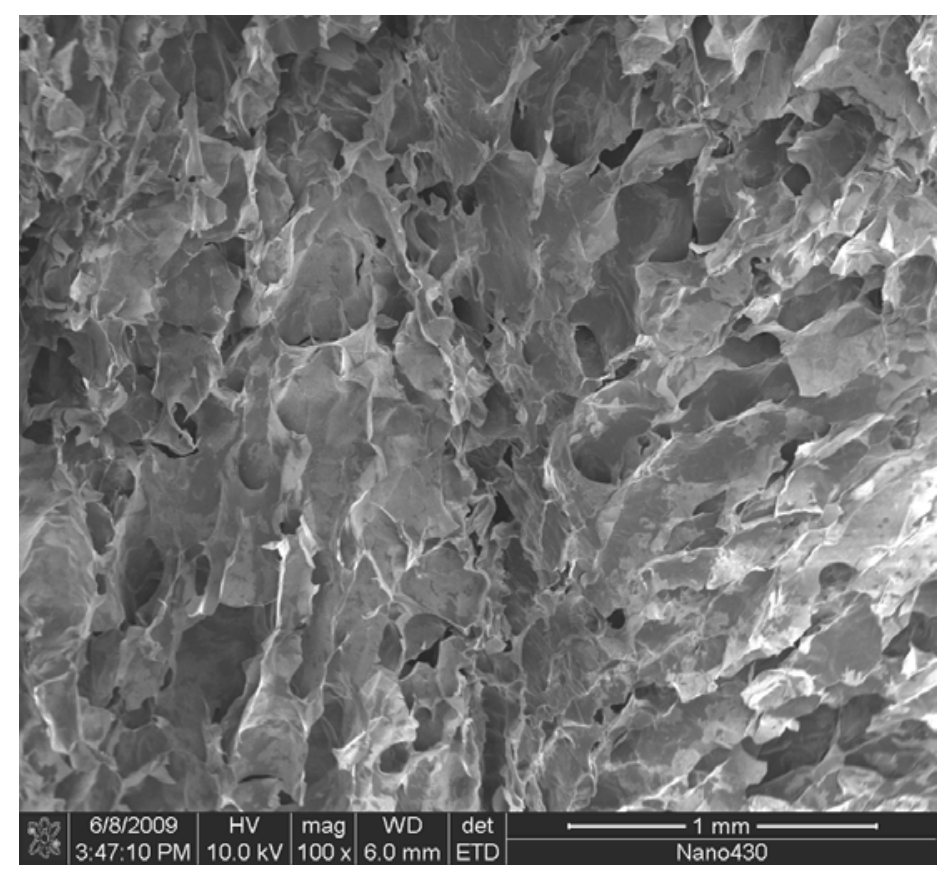

Fig. 5. SEM micrograph of hydrogels cross-sections 


\section{Antibacterial Activity}

The SEM micrographs of E. coli cells are shown in Fig. 6A and B after direct contact with agar and tests of the hydrogel at $37^{\circ} \mathrm{C}$. After $24 \mathrm{~h}$, evidence of bacterial replication is seen in the form of bacilus chains of E. coli on the control of agar (Fig. 6 A), while there are no bacilus chains visible on the hydrogel that was exposed to the same incubative conditions, though deformation and debris of bacterial cells are readily apparent (Fig. 6 B). The results indicate that the hydrogels exhibited a strong antibacterial effect against the E. coli, in contrast to the control. Although the detailed mechanism of the antibacterial effect of this material has not been determined, it is suggested that the tested hydrogel may be similar to that of other quaternary ammonium compounds (Huang et al. 2008). The negatively charged surface of $E$. coli can be absorbed onto polycationic hydrogels (Beyth et al. 2006). This process is thought to be responsible for the increasing of cell penetration ability and may cause the lysis of bacterial cells and cell membranes disruption. This may provide an explanation for the bacterial debris in our study.
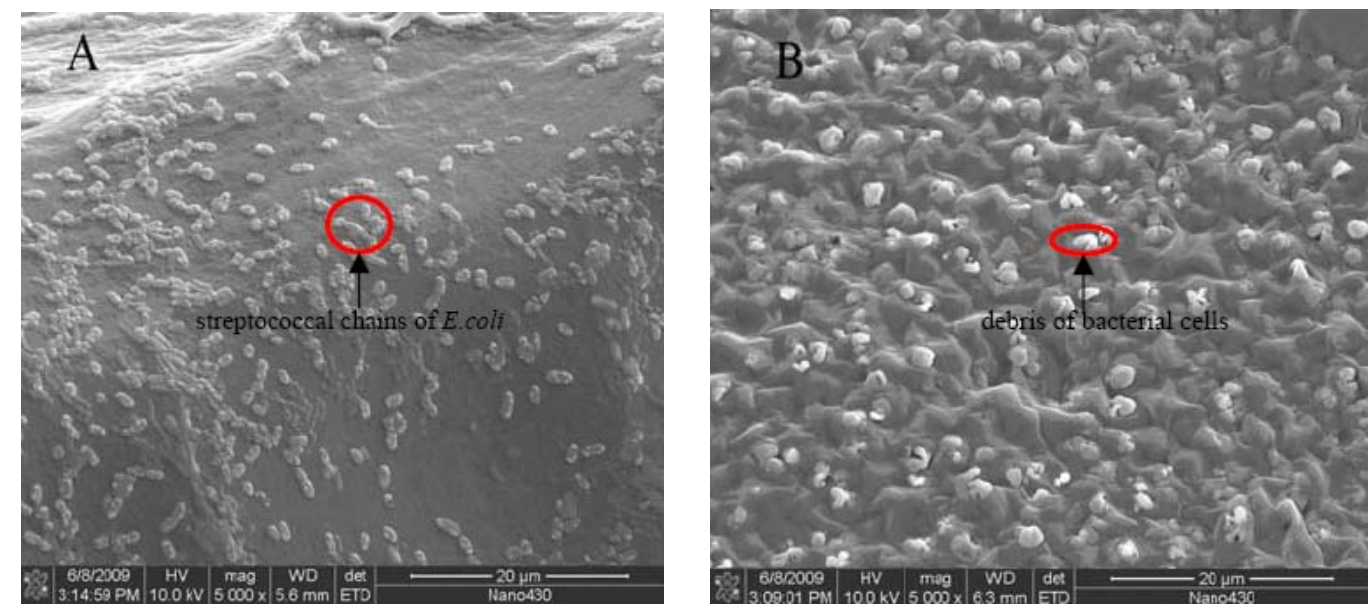

Fig.6. SEM micrograph (magnification $\times 5000$ ) of E.coli cells in direct with samples after $24 \mathrm{~h}$ incubation of $37^{\circ} \mathrm{C}$. (A) the control sample of agar; (B) the tested hydrogel

\section{CONCLUSIONS}

1. Novel salt-sensitive and antibacterial hydrogels with quaternary ammonium groups were prepared via ether-forming and crosslinking reactions.

2. The FT-IR analysis showed that new quaternary ammonium groups were grafted to cellulose. The content of free water and bound water in $\mathrm{QC} / \mathrm{ECH}$ hydrogels were $78.41 \%$ and $20.48 \%$, respectively, by DSC analysis.

3. Swelling experiments showed that the hydrogels had a rapid response rate and saltsensitive behavior.

4. Deformation and debris of bacterial cells were readily observed on the surface of the hydrogels by SEM. The results show that the hydrogels exhibited a strong antibacterial effect against the E.coli. 


\section{ACKNOWLEDGMENTS}

This work was supported by National High Technology Program 863 (No.2007AA100704).

\section{REFERENCES CITED}

Agrawal, A. M., Manek, R. V., Kolling, W. M., and Neau, S. H. (2004). "Water distribution studies within microcrystalline cellulose and chitosan using differential scanning calorimetry and dynamic vapor sorption analysis," J. Pharm. Sci. 93(7), 1766-1779.

Andresen, M., Stenstad, P., Moretro, T., Langsrud, S., Syverud, K., Johansson, L. S., and Stenius, P. (2007). "Nonleaching antimicrobial films prepared from surface-modified microfibrillated cellulose," Biomacromolecules 8(7), 2149-2155.

Bai, Y. X., and Li, Y. F. (2006). "Preparation and characterization of crosslinked porous cellulose beads," Carbohydr. Polym. 64(3), 402-407.

Beyth, N., Farber, I. Y., Bahir, R., Domb, A. J., and Weiss, E. I. (2006). “Antibacterial activity of dental composites containing quaternary ammonium polyethylenimine nanoparticles against Streptococcus mutants," Biomaterials 27(21), 3995-4002.

Chang, C. Y., Lue, A., and Zhang, L. A. (2008). "Effects of crosslinking methods on structure and properties of cellulose/PVA hydrogels," Macromol. Chem. Phys. 209(12), 1266-1273.

Dizman, B., Elasri, M. O., and Mathias, L. J. (2006). "Synthesis and antibacterial activities of water-soluble methacrylate polymers containing quaternary ammonium compounds," J. Polym. Sci. Part A: Polym. Chem. 44(20), 5965-5973.

Gristina, A., and Sherk, H. H. (1987). "Biomaterial-centered infection: Microbial adhesion versus tissue integration," Science 237(4822), 1588-1595.

Hamidi, M., Azadi, A., and Rafiei, P. (2008). "Hydrogel nanoparticles in drug delivery," Adv. Drug Delivery Rev. 60(15), 1638-1649.

Huang, J. Y., Koepsel, R. R., Murata, H., Wu, W., Lee, S. B., Kowalewski, T., Russell, A. J., and Matyjaszewski, K. (2008). "Nonleaching antibacterial glass surfaces via "Grafting Onto": The effect of the number of quaternary ammonium groups on biocidal activity," Langmuir 24(13), 6785-6795.

Jampala, S. N., Sarmadi, M., Somers, E. B., Wong, A. C. L., and Denes, F. S. (2008). "Plasma-enhanced synthesis of bactericidal quaternary ammonium thin layers on stainless steel and cellulose surfaces," Langmuir 24(16), 8583-8591.

Kopeček, J., and Yang, J. Y. (2007). "Hydrogels as smart biomaterials," Polym. Int. 56(9), 1078-1098.

Kuo, Y. N., and Hong, J. (2005). "Investigation of solubility of microcrystalline cellulose in aqueous NaOH," Polym. Adv. Technol. 16(5), 425- 433.

Leelamma, P. N., and Devaky, K. S. (2009). "Synthesis of polymer-supported quaternary ammonium salts and their phase-transfer catalytic activity in halogen-exchange reactions," J. Appl. Polym. Sci. 112(5), 2750-2756. 
Liu, H. X., Wang, C. Y., Gao, Q. X., Liu, X. X., and Zhen, T. ( 2008). "Fabrication of novel core-shell hybrid alginate hydrogel beads," Int. J. Pharm. 351(1-2), 104-112.

Marandi, G. B., Sharifnia, N., and Hosseinzadeh, H. (2006). "Synthesis of an alginatepoly (sodium acrylate-co-acrylamide) superabsorbent hydrogel with low salt sensitivity and high pH sensitivity," J. Appl. Polym. Sci. 101(5), 2927-2937.

Mohamed, M. H. (2006). "Development of a one-stage process for pretreatment and cationisation of cotton fabric," Color. Technol. 122(3), 135-144.

Mohan, Y. M., Lee, K., Premkumar, T., and Geckeler, K. E. (2007). "Hydrogel networks as nanoreactors: A novel approach to silver nanoparticles for antibacterial applications," Polymer 48(1), 158-164.

Nuttelman, C. R., Rice, M. A., Rydholm, A. E., Salinas, C. N., Shan, D. N., and Anseth, K.S. (2008). "Macromolecular monomers for the synthesis of hydrogel niches and their application in cell encapsulation and tissue engineering," Prog. Polym. Sci. 33(2), 167-179.

Obara, K., Ishihara, M., Ishizuka, T., Fujita, M., Ozeki, Y., Maehara, T., Saito, Y., Yura, H., Matsui, T., Hattori, H., Kikuchi, M., and Kurita, A. (2003). "Photocrosslinkable chitosan hydrogel containing fibroblast growth factor-2 stimulates wound healing in healing-impaired db/db mice," Biomaterials 24(20), 3437-3444.

Pal, S., Mal, D., and Singh, R. P. (2005). "Cationic starch: An effective flocculating agent," Carbohydr. Polym. 59(4), 417-423.

Potera, C. (1999). "Forging a link between biofilms and diseases," Science 283, 18371839.

Roy, D., Knapp, J. S., Guthrie, J. T., and Perrier, S. (2008). “Antibacterial cellulose fiber via RAFT surface graft polymerization,” Biomacromolecules 9(1), 91-99.

Roy, S., and Das, P. K. (2008). "Antibacterial hydrogels of amino acid-based cationic amphiphiles," Biotechnol. Bioeng. 100(4), 756-764.

Sajomsang, W., Gonil, P., and Tantayanon, S. (2009). "Antibacterial activity of quaternary ammonium chitosan containing mono or disaccharide moieties: Preparation and characterization," Int. J. Biol. Macromol. 44(5), 419-427.

Salick, D. A., Kretsinger, J. K., Pochan, D. J., and Schneider, J. P. (2007). "Inherent antibacterial activity of a peptide-based beta-hairpin hydrogel," J. Am. Chem. Soc. 129 (47), 14793-14799.

Sanchez, M. S., Pradas, M. M., and Ribelles, J. L. G. (2004). "Thermal transitions in PHEA hydrogels by thermomechanical analysis. A comparison with DSC data," Eur. Polym. J. 40(2), 329-334.

Song, Y. B., Sun, Y. X., Zhang, X. Z., Zhou, J. P., and Zhang, L. N. (2008). "Homogeneous quaternization of cellulose in $\mathrm{NaOH} /$ urea aqueous solutions as gene carriers," Biomacromolecules 9(8), 2259-2264.

Silva, D. A., Feitosa, J. P. A., and Maciel, J. S., et al. (2006). "Characterization of crosslinked cashew gum derivatives," Carbohydr. Polym. 66(1), 16-26.

Stabenfeldt, S. E., Garcia, A. J., and LaPlaca, M. C. (2006). "Thermoreversible lamininfunctionalized hydrogel for neural tissue engineering," J. Biomed. Mater. Res. Part A 77A(4), 718-725. 
Su, J. C., Liu, S. Q., Joshi, S. C., and Lam, Y. C. (2008). "Effect of SDS on the gelation of hydroxypropylmethylcellulose hydrogels," J. Therm. Anal. Calorim. 93(2), 495501.

Thorsteinsson, T., Masson, M., Kristinsson, K. G., Hjalmarsdottir, M. A., Hilmarsson, H., and Loftsson, T. (2003). "Soft antimicrobial agents: Synthesis and activity of labile environmentally friendly long chain quaternary ammonium compounds," J. Med. Chem. 46(19), 4173- 4181.

Wang, S. G., Sun, X. F., Liu, X. W., Gong, W. X., Gao, B. Y., and Bao, N. (2008). "Chitosan hydrogel beads for fulvic acid adsorption: Behaviors and mechanisms," Chem. Eng. J. 142(3), 239-247.

Wu, Z. M., Zhang, X. G., Zheng, C., Li, C. X., Zhang, S. M., Dong, R. N., and Yu, D. M. (2009). "Disulfide-crosslinked chitosan hydrogel for cell viability and controlled protein release," Eur. J. Pharm. Sci. 37(3-4), 198-206.

Zhao, Y., Kang, J., and Tan, T. W. (2006). "Salt-, pH- and temperature-responsive semiinterpenetrating polymer network hydrogel based on poly(aspartic acid) and poly(acrylic acid)," Polymer 47(22), 7702-7710.

Article submitted: Dec. 22, 2009; Peer review completed: April 9, 2010; Revised version received and accepted: April 13, 2010; Published: April 15, 2010. 